\section{Concordance between estimated glomerular filtration rate using equations and that measured using an imaging method}

\author{
CAMILO A. GONZÁLEZ G. ${ }^{1,2,3}$, ALEJANDRO DURÁN CAMERO², \\ MARÍA TERESA VARGAS ${ }^{2}$, PAOLA K. GARCÍA ${ }^{1,2}$, \\ KATEIR CONTRERAS ${ }^{1,2}$, PATRICIA RODRÍGUEZ ${ }^{1,2}$
}

\begin{abstract}
Background: Guidelines recommend estimating glomerular filtration rate (GFR) using creatinine-based equations (CBE). Aim: To evaluate the agreement between GFR measured using radionuclide imaging and estimated using creatinine-based equations. Material and Methods: In 421 patients aged 54 \pm 17 years (47\% women) GFR was estimated using the MDRD-4, CKD-EPI and the body surface adjusted Cockroft Gault equation. GFR was also measured using a radionuclide imaging method with ${ }^{99} \mathrm{mTc}-\mathrm{DTPA}$. The concordance between estimated and measured GFR was calculated using Lin's concordance coefficient and Bland and Altman plots. Results: Average GFR values obtained with CKD-EPI, MDRD-4, body surface adjusted Cockroft Gault equation and ${ }^{99} \mathrm{mTc}$-DTPA imaging were 75.9 $\pm 26.6,76.3 \pm 28.8,77.1 \pm 31.6$ and $77.9 \pm$ $28.4 \mathrm{ml} / \mathrm{min} / 1.73 \mathrm{~m}^{2}$, respectively. There was no significant difference in means and 29\% of participants had a GFR $<60 \mathrm{ml} / \mathrm{min} / 1.73 \mathrm{~m}^{2}$ by CKD-EPI. The correlation was good between equations, but acceptable when compared with the ${ }^{99} \mathrm{mTc}$-DTPA imaging. The weighted kappa between CBEs was good, but low when comparing CBEs with measured GFR. The Lin's concordance coefficient between estimated and measured GFR was low. Conclusions: GFR measured by ${ }^{99} \mathrm{mTc}$-DTPA radionuclide imaging has a low correlation and poor concordance with estimations using $C B E$.
\end{abstract}

(Rev Med Chile 2021; 149: 13-21)

Key words: Glomerular Filtration Rate; Kidney Function Tests; Radionuclide Imaging; Renal Insufficiency, Chronic.

\section{Concordancia entre la tasa de filtración glomerular estimada con ecuaciones y aquella medida mediante imágenes}

Antecedentes: Las guías clínicas recomiendan estimar la tasa de filtración glomerular (TFG) usando ecuaciones basadas en la creatinina sérica. Objetivo: Estudiar la concordancia entre la TFG medida usando un método de imágenes usando radioisótopos y aquella estimada con ecuaciones. Material y Métodos: En 421 pacientes de $54 \pm 17$ años (47\% mujeres), la TFG se estimó utilizando las

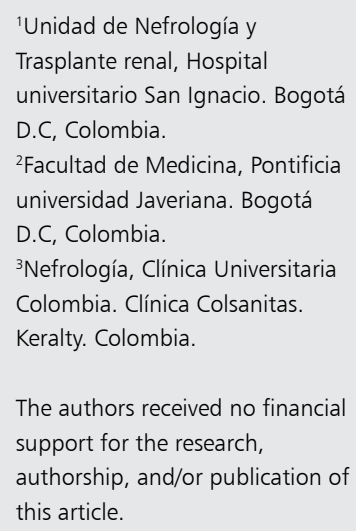

The authors received no financial support for the research, authorship, and/or publication of this article.

The authors have no conflict of interest to declare.

Recibido el 14 de marzo de 2020 aceptado el 9 diciembre de 2020.

\section{Correspondence:}

Camilo Alberto González

González

Hospital Universitario San Ignacio. Pontificia Universidad Javeriana.

Carrera 7 \# 40-62. 6th floor. Renal Services. Bogotá, Colombia. cagonzalez@husi.org.co 
ecuaciones MDRD-4, CKD-EPI y Cockroft Gault ajustada para superficie corporal. La TFG se midió también con una técnica de imágenes usando ${ }^{99} \mathrm{mTc}-\mathrm{DTPA}$. La concordancia entre la estimación y medición se calculó usando el coeficiente de concordancia de Lin y gráficos de Bland y Altman. Resultados: Los promedios de TFG obtenidos con CKD-EPI, MDRD-4, ecuación de Cockroft Gault e imágenes con ${ }^{99} m T c$-DTPA fueron 75,9 $\pm 26,6,76,3 \pm 28,8,77,1 \pm 31,6$ y 77,9 $\pm 28,4 \mathrm{ml} / \mathrm{min} / 1,73 \mathrm{~m}^{2}$, respectivamente. No hubo diferencias significativas en los promedios y el 29\% de los participantes tuvo una TFG $<60 \mathrm{ml} / \mathrm{min} / 1,73$ $\mathrm{m}^{2}$. La correlación entre las ecuaciones fue buena, pero sólo aceptable cuando se comparó con la medición por imágenes. El kappa ajustado entre las ecuaciones fue adecuado, pero malo cuando se comparó las ecuaciones con la medición por imágenes. El coeficiente de Lin mostró una baja concordancia entre la estimación y medición de TFG. Conclusiones: La concordancia entre la estimación de TFG usando ecuaciones y su medición directa mediante imágenes es baja.

Palabras clave: Insuficiencia Renal Crónica; Pruebas de Función Renal; Cintigrafía; Tasa de Filtración Glomerular.

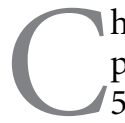
hronic kidney disease (CKD) is a global public health problem. Approximately 500 million people worldwide have some degree of $\mathrm{CKD}^{1,2}$ Glomerular filtration rate (GFR) is accepted as the best indicator of renal function, and its measurement in clinical practice is crucial, not only to diagnose CKD, but also to adequately stratify its severity, establish interventions and predict outcomes $^{3-6}$. Traditionally, inulin clearance has been the gold standard to measure GFR, but it has important logistical difficulties for clinical massive use, even for experimental trial use. Clearance of some substances such as iothalamate, Cr-EDTA (Chromium-51 ethylenediamine tetraacetic acid), DTPA (diethylenetriaminepentaacetic acid) or iohexol, easier to detect in fluids and with simpler protocols, has become a benchmark equivalent of measured GFR (mGFR) gold standard without really being the most accurate methods ${ }^{7}$. These tools are difficult to use and expensive, and their repetitive use in the clinical setting is limited, Thus, they are mainly used for trials instead of renal inulin clearance. This systematically justifies the use of endogenous GFR markers, such as creatinine, and equations, to estimate GFR in the clinical practice ${ }^{3}$.

The method recommended by the National Kidney Disease Education Program, the National Institute of Diabetes and Digestive and Kidney Diseases, the National Kidney Foundation and the American Society of Nephrology to estimate GFR (eGFR) is based on the measurement of standar- dized serum creatinine and its derived equations (MDRD-4 and CKD-EPI). All these equations lack an appropriate validation to the GFR in which they were applied, given that the method for measuring creatinine was not standardized in the different countries, and this introduced heterogeneity into the measurements ${ }^{8,9}$.

Furthermore, estimates based on creatinine have several disadvantages, depend on multiple variables, and their accuracy is still under deba$\mathrm{te}^{10,11}$. CBEs have been validated and adjusted in the Japanese, American, Australian, Spanish and Chinese populations ${ }^{12-14}$. The performance of these in the Colombian population is unknown, and we will be limited to validate them in the absence of a gold standard test.

In Colombia, under special conditions in which error in the estimation of GFR with CBE is expected, we usually measure GFR with nuclear medicine using ${ }^{99 \mathrm{~m}}$ Tc-DTPA (Technetium-99 diethylenetriaminepentaacetic acid). This is a renal radiopharmaceutical marker available for nuclear imaging, which is filtered only by the glomerulus and, therefore, could be used to $\mathrm{mGFR}^{15}$. It is a simple and fast procedure, and although it is frequently used to study renovascular hypertension and obstructive uropathy, its availability is limited and is very expensive. The most commonly used and commercially available measurement method is the modified Gates method, which does not require blood or urine samples and only takes approximately 20 minutes ${ }^{16}$. Due to its convenien- 
ce, it has been used in multiple clinical studies as a surrogate GFR marker ${ }^{17}$, and also as a gold standard in some studies on performance evaluation of CKD-EPI equation ${ }^{11,12,18-20}$. Despite this, it is unknown whether this method is more accurate than $\mathrm{CBE}$, and some studies have recently questioned its accuracy; for example, it is not recommended in international guidelines as a gold standard to generate or validate the use of equations. Within the expected biases are the hydration status, the degree of CKD, the presence of obesity or malnutrition, distance from the gamma camera to the patient, technical biases when selecting the area of the renal silhouette, and biases in the estimation of a geometrically asymmetric area ${ }^{21-23}$. The objective of this study was to estimate the correlation and diagnostic concordance of eGFR by CBE, with that obtained by ${ }^{99 \mathrm{~m}} \mathrm{Tc}-\mathrm{DTPA}$ radionuclide imaging.

\section{Methods}

\section{Study population and data collection}

The study was carried out in 4 institutions in Bogotá, Colombia. A search was made with adult patients who underwent ${ }^{99 \mathrm{~m}} \mathrm{Tc}$-DTPA radionuclide imaging for standardized GFR measurement and who had a standardized serum creatinine value available for 2 weeks around the study indicated under physician clinical criteria, without GFR restriction. All possible sources of error in creatinine were excluded to adequately estimate GFR: acute kidney injury (AKI defined by KDIGO creatinine criteria), people at extremes of body mass index $\left(\mathrm{BMI}<18\right.$ and $\left.>35 \mathrm{~kg} / \mathrm{m}^{2}\right)$ and pregnant women; as well as the possible sources of error in the radionuclide imaging such as severe obesity with BMI greater than $35 \mathrm{~kg} / \mathrm{m}^{2}$, severe malnutrition with $\mathrm{BMI}<18 \mathrm{~kg} / \mathrm{m}^{2}$, AKI, dehydration described in the medical record, more than 4 renal cysts per renal unit and obstruction of the urinary tract. All demographic data were collected, including dates, age, race, sex, weight, height, BMI, BSA, serum creatinine from which GFR is estimated by CKD-EPI equations, 4-variable MDRD, and Cockroft Gault adjusted to BSA. The GFR result by radionuclide imaging was adjusted to $1,73 \mathrm{~m}^{2}$ of BSA.

\section{Measurement of serum creatinine and eGFR:}

Serum creatinine was measured using an enzymatic technique (modular P Analyzer, Crea- tinine plus assay, Roche Diagnostics, Mannheim, Germany). Serum levels were obtained from the laboratory database, as long as the sample had been collected and processed within two weeks of the radionuclide imaging. eGFR by MDRD was calculated using the 4 -variable equation ${ }^{24}$.

$$
\begin{gathered}
\text { eGFR MDRD }-4=175 x(\text { serum } C r)^{-1.154} x \\
(\text { age in years })^{-0.203} x(0.742 \text { if woman }) x
\end{gathered}
$$$$
\text { (1.210 if black race) }
$$

eGFR CKD-EPI was calculated using the equation developed in $2009^{8}$

$$
\begin{gathered}
=141 \times \min (\text { serum } C r / \kappa, 1)^{\alpha} \times \max (\text { serum } \\
C r / \kappa, 1)^{-1.209} \times\left(0.993^{\text {Age }} \mathrm{x}(1.018 \text { if woman }) x\right. \\
(1.159 \text { if black race })
\end{gathered}
$$

Likewise, creatinine clearance was estimated by the Cockroft Gault (CG) equation: (140- Age * Weight ${ }^{\star} 0.85$ if woman $) /\left(72{ }^{\star}\right.$ Creatinine $(\mathrm{mg} /$ $\mathrm{dL})$ ) and adjusted to a BSA of $1.73 \mathrm{~m}^{2}$ to make a comparison between patients ${ }^{25}$.

\section{Radionuclide imaging of glomerular filtration with ${ }^{99 m}$ Tc-DTPA}

It was performed by intravenous injection of 99mTc-DTPA (2-3 mCi or 74-111 MBq). Thirty minutes before starting the study, patients drank $500 \mathrm{ml}$ of water to achieve adequate hydration and a urinary flow of at least $1-3 \mathrm{ml} / \mathrm{min}$ during the study. The study was performed with the patient in supine position on the gamma camera detection head. Flat dynamic images, obtained from the posterior projection of the upper abdomen region (kidney beds), were taken at 2 seconds per frame during the first minute (renal perfusion phase), 15 seconds per frame ( 4 frames per minute) for 6 minutes, and finally 13 frames each of 60 seconds during the rest of the study (parenchymal and excretion phases, respectively). The total duration of the study was 20-60 minutes, depending on the indication, and the GFR values were calculated with the Gates method.

\section{Sample size}

The minimum recommended sample size was taken to estimate Cohen's kappa coefficient of 5 non-proportional categories, considering a power of $80 \%$ and an alpha error of 0.05 . Two pre-established kappa values were taken based on the literature: 0.5 and 0.6 . The minimum sample size is 373 patients ${ }^{26}$. 


\section{Study design and statistical analysis}

We performed a correlation-concordance study for methods of GFR evaluation. The analysis was made with the Stata ${ }^{\circledR} 12.0$ software for the Mac OS ${ }^{\circledR}$ package. Numerical data were expressed as medians or means and ranges or standard deviation according to distribution, and the categorical variables as numbers and percentages. The Wilcoxon rank sum test was used to compare non-normal variables and t-test for normal distribution. Correlation between eGFR by CBE and mGFR was evaluated using the Spearman correlation coefficient. Concordance was estimated using Cohen's kappa coefficient for two strata with a cut-off of $60 \mathrm{ml} / \mathrm{min} / 1.73 \mathrm{~m}^{2}$ and the weighted kappa estimation for 3 arbitrary strata and 5 strata, like CKD classification; however the patient did not have criteria for CKD diagnosis. The absolute precision of the result was estimated, defined as the difference between the value of the kappa coefficient and the lower limit of the confidence interval, using EPIDATA ${ }^{\circledR} 4.0$ for MAC-OS ${ }^{\circledR}$. Finally, Lin’s concordance correlation coefficient was estimated, and it was expressed graphically with the limits of agreement of Bland-Almant. A p-value $<0.05$ is assumed to be statistically significant.

\section{Ethics}

The research and ethics committee of each of the included centers approved the protocol.

\section{Results}

We found 618 radionuclide images with ${ }^{99 m}$ Tc-DTPA to measure glomerular filtration; 101 were discarded by exclusion criteria (extremes of body mass and acute kidney injury), and 96 by incomplete data. We analyzed 421 patients with studies performed between November 2008 and October 2017.

Demographic and clinical data of 421 included patients were summarized on Table 1 . The majority of patients have normal eGFR. The $29.4 \%$ of patients has less than $60 \mathrm{ml} / \mathrm{min} / 1.73 \mathrm{~m}^{2}$ by CKD-EPI equations and only $4.2 \%$ less than $30 \mathrm{ml} / \mathrm{min} / 1.73 \mathrm{~m}^{2}$. Table 2 shows distribution according to each compared GFR method. The proportion of patients with eGFR less than $30 \mathrm{ml} /$ $\mathrm{min} / 1.73 \mathrm{~m}^{2}$ was low.

The mean difference between CKD-EPI and
MDRD-4 was not significant ( $\mathrm{p}=0.85)$; it was not significant between CKD-EPI and BSA adjusted $C G(p=0.57)$, nor between CKD-EPI and that measured by ${ }^{99 \mathrm{~m} T c-D T P A}(\mathrm{p}=0.31)$.

Figure 1 shows the distribution of the filtration measured by ${ }^{99 \mathrm{~m}} \mathrm{Tc}-\mathrm{DTPA}$ and that estimated by the different equations according to 5 strata like CKD classification using the CKD-EPI equation as recommended by guidelines. The distribution of values by equations are proportionally symmetric; however, we can see how values by mGFR with 99mTc-DTPA, had a disproportionate distribution compared with GFR by all equations

\section{Table 1. Summary of demographic and clinical data}

\begin{tabular}{|lr|}
\hline Variable & \multicolumn{1}{c|}{ Value } \\
\hline Age, mean (SD), years & $54( \pm 17.1)$ \\
Female, $\mathrm{n}(\%)$ & $155(46.8)$ \\
Weight, mean (SD), $\mathrm{Kg}$ & $68( \pm 13.9)$ \\
Height, mean (SD), cm & $164( \pm 9.4)$ \\
BMl, mean (SD), Kg/m² & $25( \pm 4.14)$ \\
BSA, mean (SD), m² & $1.75( \pm 0.21)$ \\
Creatinine, mean (SD), mg/dL & $1.16( \pm 1.05)$ \\
mGFR, mean (SD), ml/min/1.73 m² & $77.9( \pm 28.4)$ \\
eGFR, CKD-EPI mean (SD), ml/min/1.73 $\mathrm{m}^{2}$ & $75.9( \pm 26.6)$ \\
eGFR MDRD-4 mean (SD), ml/min/1.73 $\mathrm{m}^{2}$ & $76.3( \pm 28.8)$ \\
eGFR CG adjusted to BSA mean (SD), & $77.1( \pm 31.6)$ \\
\hline $\mathrm{ml} / \mathrm{min} / 1.73 \mathrm{~m}^{2}$ & \\
\hline
\end{tabular}

SD: standard deviation, Kg: kilograms, cm: centimeters, $\mathrm{m}$ : meter, mg milligrams, dL: deciliter. BMI: body mass index, BSA body surface area. eGFR: estimated gloemerular filtration rate, $\mathrm{mGFR}$ : measured glomerular filtration rate, $\mathrm{mL}$ milliliters, min: minute.

Table 2. GFR distribution by equations and MGFR by ${ }^{99 m}$ Tc-DTPA

\begin{tabular}{|lccc|}
\hline GFR $\mathbf{~ m l} / \mathbf{m i n} / \mathbf{1 . 7 3} \mathbf{~ m}^{\mathbf{2}}$ & $\mathbf{2} \mathbf{6 0}$ & $\mathbf{3 0 - 5 9}$ & $<\mathbf{3 0}$ \\
mGFR & $74.1 \%$ & $23.3 \%$ & $2.6 \%$ \\
CKD EPI & $70.5 \%$ & $25.3 \%$ & $4.27 \%$ \\
MDRD-4 & $71.9 \%$ & $23.9 \%$ & $4.2 \%$ \\
CG BSA & $70.3 \%$ & $25.7 \%$ & $4 \%$ \\
\hline
\end{tabular}

BSA body surface area. eGFR: estimated gloemerular filtration rate, mGFR: measured glomerular filtration rate, $\mathrm{mL}$ milliliters, min: minute. 


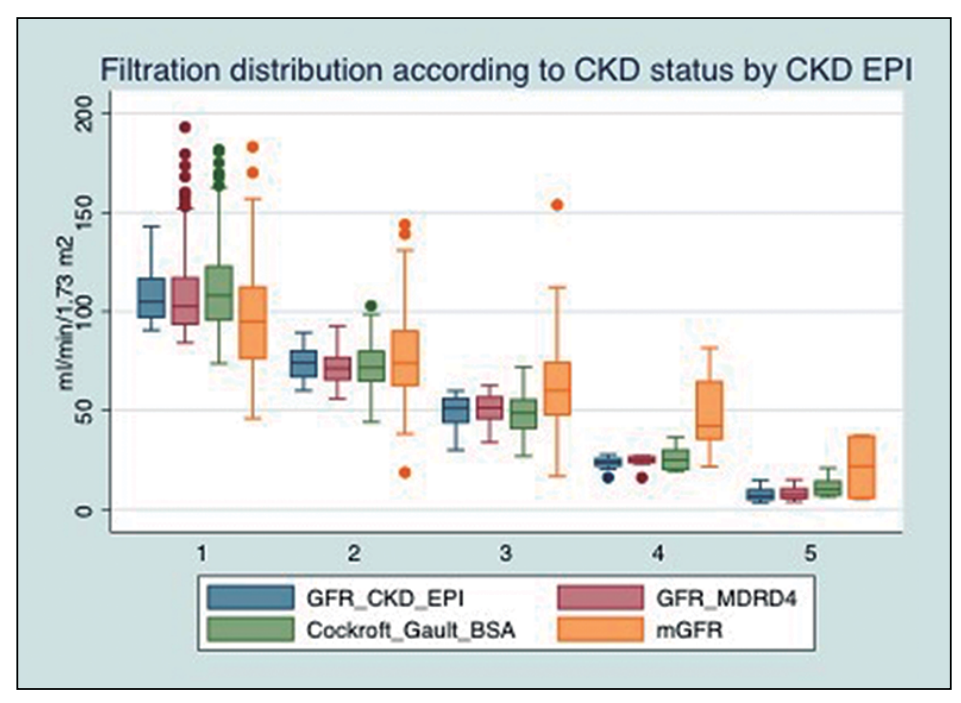

Figure 1. Box plot distribution of GFR based on 5 strata such as CKD classification by CKD-EPI equation. The figure shows the distribution of the values by each GFR method. The distribution of GFR measured by 99mTc-DTPA tends to leave the extremes of each degree of CKD classification according to CKD-EPI.
Table 3 shows a Spearman correlation between equations and mGFR by ${ }^{99 m}$ Tc-DTPA, There are high correlation between equations, but not between equations and mGFR.

The estimation of the concordance was made

Table 3. Correlation coefficient (Spearman)

\begin{tabular}{|lccc|}
\hline & CKD-EPI & MDRD4 & 99mTc-DTPA \\
\hline MDRD4 & 0.98 & - & - \\
CGa & 0.94 & 0.91 & 0.50 \\
99mTC-DTPA & 0.57 & 0.55 & - \\
\hline
\end{tabular}

$\mathrm{p}<0.00001$. CKD-EPI: chronic kidney disease epidemiology collaboration equation. MDRD4: 4 variable modification of diet in renal disease equation. CGa: body surface adjusted Cockroft Gault equation. ${ }^{99 m}$ Tc-DTPA: Technetium-99 diethylenetriaminepentaacetic acid. by Cohen's kappa concordance coefficient for the cut point of $\geq$ or $<60 \mathrm{~mL} / \mathrm{min} / 1.73 \mathrm{~m}^{2}$, and an almost perfect diagnostic agreement was obtained between MDRD-4 and CKD-EPI, considerable between CKD-EPI and CG BSA adjusted, considerable between MDRD-4 and CG BSA adjusted, and low concordance between mGFR and all the equations included in the evaluation (Table 4).

When stratifying according to 5 strata, like CKD classification, and according to arbitrary cutoff points of 30 and $60 \mathrm{~mL} / \mathrm{min} / 1.73 \mathrm{~m}^{2}$, we confirmed the inadequate concordance between the glomerular filtration estimated by the equations and the mGFR, and its kappa worsens when it is stratified like CKD classification (5 strata) compared to only 2 strata $(\mathrm{p}<0.04)$ (Tables 5 and 6$)$.

Considering the sample of 421 patients, a CKD ratio of $29.8 \%$ with CKD EPI and $25.9 \%$ with mGFR and a Kappa coefficient of 0.41 , the abso-

Table 4. Concordance for CKD diagnosis (Cohen's kappa coefficient)

\begin{tabular}{|cccc|}
\hline & CKD-EPI & MDRD4 & 99mTC-DTPA \\
\hline MDRD4 & $0.91 \mathrm{Cl}(0.87-0.96)$ & - & - \\
\hline CGa & $0.80 \mathrm{Cl}(0.73-0.86)$ & $0.73 \mathrm{Cl}(0.66-0.81)$ & $0.38 \mathrm{Cl}(0.28-0.48)$ \\
\hline 99mTc-DTPA & $0.41 \mathrm{Cl}(0.31-0.50)$ & $0.41 \mathrm{Cl}(0.31-0.51)$ & - \\
\hline
\end{tabular}

${ }^{*} \mathrm{Cl}$ : 95\% confidence interval. All with p-value <0.00001. CKD-EPI: chJronic kidney disease epidemiology collaboration equation. MDRD4: 4-variable modification of diet in renal disease equation. CGa: body surface adjusted Cockroft Gault equation. 99mTc-DTPA: Technetium-99 diethylenetriaminepentaacetic acid. 
Table 5. Concordance for 3 strata (Cohen's kappa coefficient)

\begin{tabular}{|cccc|}
\hline & CKD-EPI & MDRD4 & 99mTc-DTPA \\
\hline MDRD4 & $0.93 \mathrm{Cl}(0.89-0.97)$ & - & - \\
\hline CGa & $0.79 \mathrm{Cl}(0.72-0.85)$ & $0.72 \mathrm{Cl}(0.65-0.79)$ & $0.34 \mathrm{Cl}(0.24-0.43)$ \\
\hline${ }^{99 m}$ Tc-DTPA & $0.38 \mathrm{Cl}(0.28-0.47)$ & $0.37 \mathrm{Cl}(0.28-0.46)$ & - \\
\hline
\end{tabular}

${ }^{*} \mathrm{Cl}$ : 95\% confidence interval. All with p-value $<0.00001$. CKD-EPI: chronic kidney disease epidemiology collaboration equation. MDRD4: 4 variable modification of diet in renal disease equation. CGa: body surface adjusted Cockroft Gault equation. 99mTc-DTPA: Technetium-99 diethylenetriaminepentaacetic acid.

Table 6. Concordance for CKD classification in 5 strata (Cohen's kappa coefficient)

\begin{tabular}{|cccc|}
\hline & CKD-EPI & MDRD4 & 99mTC-DTPA \\
\hline MDRD4 & $0.89 \mathrm{Cl}(0.85-0.92)$ & - & - \\
\hline CGa & $0.75 \mathrm{Cl}(0.69-0.80)$ & $0.66 \mathrm{Cl}(0.60-0.72)$ & $0.24 \mathrm{Cl}(0.17-0.31)$ \\
\hline $99 \mathrm{~m} T \mathrm{TC}-\mathrm{DTPA}$ & $0.29 \mathrm{Cl}(0.22-0.36)$ & $0.28 \mathrm{Cl}(0.20-0.35)$ & - \\
\hline
\end{tabular}

${ }^{*} \mathrm{Cl}$ : 95\% confidence interval. All with p-value $<0.00001$. CKD-EPI: chronic kidney disease epidemiology collaboration equation. MDRD4: 4 variable modification of diet in renal disease equation. CGa: body surface adjusted Cockroft Gault equation. 99mTc-DTPA: Technetium-99 diethylenetriaminepentaacetic acid.

lute accuracy (e) estimation was performed and a value of 0.096 was obtained, which is considered adequate and confirms a good sample size for the purpose of the study.

Finally, we estimate Lin's concordance correlation coefficient (CCC), and it was low for mGFR compared to eGFR with CKD-EPI (rho $\mathrm{c}=0.57$
[95\% confidence interval (CI): $0.507-0.636 \mathrm{p}=$ $0.0005]$ ), with a slope of less than 1 and a positive interception (Figure 2). We observed an important dispersion of the data with clinical relevance in the limits of agreement of Bland-Altman of $50 \mathrm{ml} /$ $\mathrm{min} / 1.73 \mathrm{~m}^{2}$, (Figure 3). The CCC between $\mathrm{mGFR}$ and all other equations was consistently low.

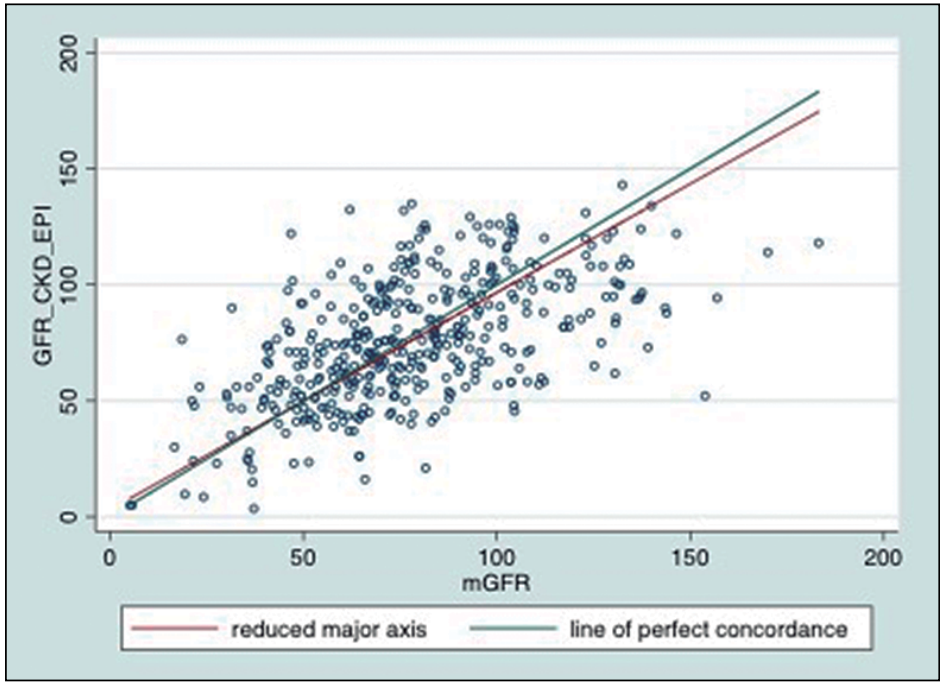

Figure 2. Lin's concordance correlation

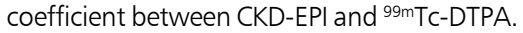
The figure shows a low CCC, with a slope of less than 1 and a positive interception. Interpreted as low agreement between GFR values measured by ${ }^{99 \mathrm{~m}} \mathrm{Tc}$-DTPA radionuclide image compared to that estimated by CKDEPI equation. 


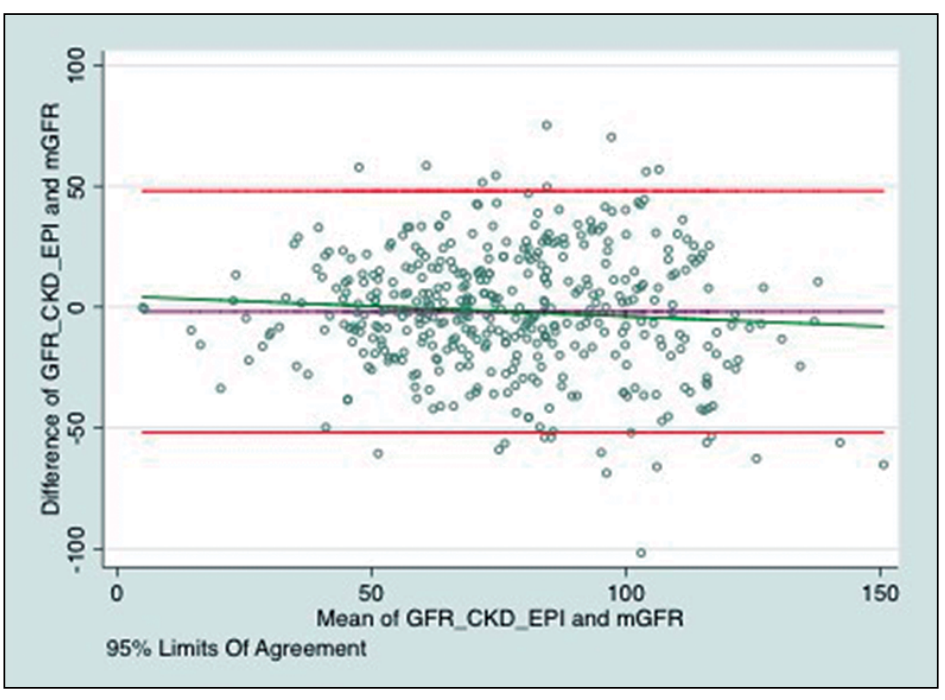

Figure 3. Bland-Altman limits of agreement. We can see that GFR average differ-

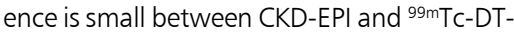
PA. However; it should be noted that this average difference is positive with low GFR values and negative with high GFR values. Likewise, the $95 \%$ limits of agreement are highly variable, equivalent to $50 \mathrm{ml} / \mathrm{min} / 1.73$ $\mathrm{m}^{2}$. Which is obviously clinically relevant, and intolerable.

\section{Discussion}

The present study includes patients from several centers in Bogotá, with an adequate sample size and a representative GFR distribution, although low proportion of patients with less than $30 \mathrm{ml} / \mathrm{min} / 1.73 \mathrm{~m}^{2}$. The Spearman correlation of the equations is adequate, due to its purely mathematical condition. However, it was bad for mGFR with respect to all eGFR equations. The study shows a low kappa concordance index for mGFR with ${ }^{99 \mathrm{~m}} \mathrm{Tc}$-DTPA radionuclide image versus eGFR with all CBEs. The same result was obtained with 3 and 5 strata like CKD classification, which indicates a low weighted agreement for diagnosis cut-off point and classification values if we considered a population with CKD. Finally a statistical test that considers both concordance and correlations such as Lin's coefficient confirms the low discriminatory capacity of mGFR compared with CKD-EPI and the others eGFR equations for defining any disease or classification based on GFR. These results are consistent with data from the literature, although some researchers are fortunate to include the gold standard ${ }^{5,6}$.

A cross-sectional study conducted in Italy with 341 CKD patients, which sought to compare the accuracy and reliability of mGFR by ${ }_{99 \mathrm{~m}} \mathrm{Tc}$-DTPA dynamic renal radionuclide image (Gates method) and eGFR by the MDRD-4 and CKD-EPI equations, concluded that mGFR tends to underestimate GFR in stages 1 and 2 of kidney disease and to overestimate it in stages 4 and 5 when compared with the equations, especially with CKD-EPI. Treatment with inhibitors of the renin-angiotensin axis and age less than 50 years accentuated the underestimation in early stages ${ }^{27}$.

Ying-Chun $\mathrm{Ma}$, et al. evaluated the performance of the ${ }^{99 \mathrm{~m}} \mathrm{Tc}-\mathrm{DTPA}$ radionuclide image in 482 CKD patients using the modified Gates method with the MDRD-4 abbreviated equation. In this study, plasma DTPA sampling (gold standard) was used, and an adequate correlation between the three measurements is shown. However, the MDRD-4 equation presented less bias and greater precision and accuracy compared with the radionuclide image. The results were consistent throughout the different stages of $\mathrm{CKD}^{17}$.

In some publications, ${ }^{99 \mathrm{~m} T c-D T P A}$ dynamic renal radionuclide image is used as a reference standard to validate and determine the operative characteristics of the different creatinine-based equations $^{33-35} \cdot{ }^{11,12,28-30}$ However, Xie P. et al., following the results of their study conducted in China, recommended against using radionuclide image as a reference method in research that seeks to validate the CKD-EPI equation. That study compared $m$ GFR by radionuclide image and that estimated by CKD-EPI with the measurement of plasma DTPA content as a gold standard; 149 CKD patients were included, and it was concluded 
that both methods can be used to establish GFR, but that CKD-EPI is more accurate, especially at rates lower than $60 \mathrm{~mL} / \mathrm{min} / 1.73 \mathrm{~m}^{2}{ }^{21}$. International guidelines do not consider ${ }^{99 \mathrm{~m}} \mathrm{Tc}-\mathrm{DTPA}$ radionuclide image as a method equivalent to the gold standard ${ }^{5,6}$.

\section{Limitations}

- In Colombia, we do not have a gold standard test to directly measure the glomerular filtration rate as measured DTPA, Cr-EDTA, iothalamate or iohexol.

- Low proportion of patients with filtration less than $30 \mathrm{ml} / \mathrm{min} / 1.73 \mathrm{~m}^{2}$.

- Retrospective nature of the information.

\section{Conclusions}

Our analysis of diagnosis agreement between CBEs recommended by guidelines for CKD diagnostics and classification and mGFR by 99mTc-DTPA radionuclide imaging was low. Based on our study and previous literature, we do not recommend using mGFR by ${ }^{99 \mathrm{~m}}$ Tc-DTPA radionuclide imaging as a diagnostic test for disease diagnosis or classification based on GFR.

\section{References}

1. Stewart JH, McCredie MR, Williams SM, Fenton SS, Trpeski L, McDonald SP, et al. The enigma of hypertensive ESRD: observations on incidence and trends in 18 European, Canadian, and Asian-Pacific populations, 1998 to 2002. American journal of kidney diseases : the official journal of the National Kidney Foundatio. 2006; 48 (2): 183-91.

2. Wakai K, Nakai S, Kikuchi K, Iseki K, Miwa N, Masakane $\mathrm{I}$, et al. Trends in incidence of end-stage renal disease in Japan, 1983-2000: age-adjusted and age-specific rates by gender and cause. Nephrology, dialysis, transplantation: official publication of the European Dialysis and Transplant Association - European Renal Associatio. 2004; 19 (8): 2044-52.

3. Stevens LA, Levey AS. Measured GFR as a confirmatory test for estimated GFR. Journal of the American Society of Nephrology : JAS. 2009; 20 (11): 2305-13.

4. De Serres SA, Varghese JC, Levin A. Biomarkers in native and transplant kidneys: opportunities to improve prediction of outcomes in chronic kidney disease. $\mathrm{Cu}$ - rrent opinion in nephrology and hypertensio. 2012; 21 (6): 619-27.

5. Group. KDIGOKCW. KDIGO 2012 clinical practice guideline for the evaluation and management of chronic kidney disease. Kidney International Supplement. 2013; 3 (1): 1 .

6. (NGC) NgNGC. Chronic kidney disease in adults: assessment and management 2014: 63.

7. Soveri I, Berg UB, Björk J, Elinder CG, Grubb A, Mejare I, et al. Measuring GFR: a systematic review. American journal of kidney diseases: the official journal of the National Kidney Foundatio. 2014; 64 (3): 411-24.

8. Levey AS, Stevens LA, Schmid CH, Zhang YL, Castro AF, 3rd, Feldman HI, et al. A new equation to estimate glomerular filtration rate. Annals of internal medicin. 2009; 150 (9): 604-12.

9. Poggio ED, Wang X, Greene T, Van Lente F, Hall PM. Performance of the modification of diet in renal disease and Cockcroft-Gault equations in the estimation of GFR in health and in chronic kidney disease. Journal of the American Society of Nephrology: JAS. 2005; 16 (2): 459-66.

10. Levey AS, Berg RL, Gassman JJ, Hall PM, Walker WG. Creatinine filtration, secretion and excretion during progressive renal disease. Modification of Diet in Renal Disease (MDRD) Study Group. Kidney international Supplemen. 1989; 27: S73-80.

11. Trimarchi H, Muryan A, Martino D, Toscano A, Iriarte $\mathrm{R}$, Campolo-Girard V, et al. Creatinine- vs. cystatin C-based equations compared with 99mTcDTPA scintigraphy to assess glomerular filtration rate in chronic kidney disease. Journal of nephrolog. 2012; 25 (6): 100315.

12. Liao Y, Liao W, Liu J, Xu G, Zeng R. Assessment of the CKD-EPI equation to estimate glomerular filtration rate in adults from a Chinese CKD population. The Journal of international medical researc. 2011; 39 (6): 2273-80.

13. Horio M, Imai E, Yasuda $Y$, Watanabe $T$, Matsuo $S$. Modification of the CKD epidemiology collaboration (CKD-EPI) equation for Japanese: accuracy and use for population estimates. American journal of kidney diseases: the official journal of the National Kidney Foundatio. 2010; 56 (1): 32-8.

14. Teruel Briones JL, Gomis Couto A, Sabater J, Fernández Lucas M, Rodríguez Mendiola N, Villafruela JJ, et al. Validación de la fórmula Chronic Kidney Disease Epidemiology Collaboration (CKD-EPI) en la insuficiencia renal crónica avanzada. Nefrología (Madrid. 2011; 31: 677-82.

15. Blaufox MD, Aurell M, Bubeck B, Fommei E, Piepsz A, Russell C, et al. Report of the Radionuclides in 
Nephrourology Committee on renal clearance. Journal of nuclear medicine: official publication, Society of Nuclear Medicin. 1996; 37 (11): 1883-90.

16. Gates GF. Split renal function testing using Tc-99m DTPA. A rapid technique for determining differential glomerular filtration. Clinical nuclear medicin. 1983; 8 (9): 400-7.

17. Ma YC, Zuo L, Zhang CL, Wang M, Wang RF, Wang HY. Comparison of $99 \mathrm{mTc}$-DTPA renal dynamic imaging with modified MDRD equation for glomerular filtration rate estimation in Chinese patients in different stages of chronic kidney disease. Nephrology, dialysis, transplantation: official publication of the European Dialysis and Transplant Association - European Renal Associatio. 2007; 22 (2): 417-23.

18. Li JT, Xun C, Cui CL, Wang HF, Wu YT, Yun AH, et al. Relative performance of two equations for estimation of glomerular filtration rate in a Chinese population having chronic kidney disease. Chinese medical journa. 2012; 125 (4): 599-603.

19. Ye X, Liu X, Song D, Zhang X, Zhu B, Wei L, et al. Estimating glomerular filtration rate by serum creatinine or/and cystatin C equations: An analysis of multi-centre Chinese subjects. Nephrology (Carlton, Vic. 2016; 21 (5): 372-8.

20. Du X, Liu L, Hu B, Wang F, Wan X, Jiang L, et al. Is the Chronic Kidney Disease Epidemiology Collaboration four-level race equation better than the cystatin $C$ equation? Nephrology (Carlton, Vic. 2012; 17 (4): 407-14.

21. Xie P, Huang JM, Liu XM, Wu WJ, Pan LP, Lin HY. (99m)Tc-DTPA renal dynamic imaging method may be unsuitable to be used as the reference method in investigating the validity of CDK-EPI equation for determining glomerular filtration rate. PloS on. 2013; 8 (5): e62328.

22. Mulligan JS, Blue PW, Hasbargen JA. Methods for measuring GFR with technetium-99m-DTPA: an analysis of several common methods. Journal of nuclear medicine: official publication, Society of Nuclear Medicin. 1990; 31 (7): 1211-9.

23. Itoh K. Comparison of methods for determination of glomerular filtration rate: Tc-99m-DTPA renography, predicted creatinine clearance method and plasma sample method. Annals of nuclear medicin. 2003; 17 (7): 561-5.

24. Levey AS, Coresh J, Greene T, Stevens LA, Zhang YL, Hendriksen $S$, et al. Using standardized serum creatinine values in the modification of diet in renal disease study equation for estimating glomerular filtration rate. Annals of internal medicin. 2006; 145 (4): 247-54.

25. Shoker A, Hossain MA, Koru-Sengul T, Raju DL, Cockcroft D. Performance of creatinine clearance equations on the original Cockcroft-Gault population. Clinical nephrolog. 2006; 66 (2): 89-97.

26. Tractenberg RE, Yumoto F, Jin S, Morris JC. Sample size requirements for training to a kappa agreement criterion on clinical dementia ratings. Alzheimer Dis Assoc Disor. 2010; 24 (3): 264-8.

27. Santoro D, Zappulla Z, Alibrandi A, Andulajevic MT, Licari M, Baldari S, et al. Cross-sectional evaluation of kidney function in hospitalized patients: estimated GFR versus renal scintigraphy. Kidney \& blood pressure researc. 2014; 39 (6): 668-76.

28. Suebmee P, Foocharoen C, Mahakkanukrauh A, Suwannaroj S, Theerakulpisut D, Nanagara R. Correlation of Glomerular Filtration Rate Between Renal Scan and Estimation Equation for Patients With Scleroderma. The American journal of the medical science. 2016; 352 (2): 166-71.

29. Kong X, Ma Y, Chen J, Luo Q, Yu X, Li Y, et al. Evaluation of the Chronic Kidney Disease Epidemiology Collaboration equation for estimating glomerular filtration rate in the Chinese population. Nephrology, dialysis, transplantation: official publication of the European Dialysis and Transplant Association - European Renal Associatio. 2013; 28 (3): 641-51.

30. Teo BW, Xu H, Wang D, Li J, Sinha AK, Shuter B, et al. GFR estimating equations in a multiethnic Asian population. American journal of kidney diseases: the official journal of the National Kidney Foundation 2011; 58 (1): 56-63. 